\title{
A review of the peri-operative management of paediatric burns: Identifying adverse events
}

\author{
H Rode, ${ }^{1}$ MB ChB, FCS (SA), MMed, FRCS (Edin); C Brink, ${ }^{1}$ MB ChB; K Bester, ${ }^{2}$ MB ChB, DA, FCA (SA); M P Coleman, ${ }^{3}$ Medical student; \\ T Baisey, ${ }^{3}$ Medical student; R Martinez, ${ }^{1} \mathrm{MB} \mathrm{ChB}$ \\ ${ }^{1}$ Department of Paediatric Surgery, Red Cross War Memorial Children's Hospital and Faculty of Health Sciences, University of Cape Town, \\ South Africa \\ ${ }^{2}$ Division Paediatric Anaesthesia, Department of Anaesthesia and Peri-operative Medicine, Faculty of Health Sciences, University of Cape Town, \\ South Africa \\ ${ }^{3}$ University of North Carolina at Chapel Hill, NC, USA
}

Corrresponding author: H Rode (heinz.rode@uct.ac.za)

\begin{abstract}
Background. Burn injuries are common in poverty-stricken countries. The majority of patients with large and complex burns are referred to burn centres. Of the children who qualify for admission, according to burn admission criteria, about half require some kind of surgical procedure to obtain skin cover. These range from massive full-thickness fire burns to skin grafts for small, residual unhealed wounds. Burn anaesthetic procedures are of the most difficult to perform and are known for high complication rates. Reasons include peri-operative sepsis, bleeding, issues around thermoregulation, the hypermetabolic state, nutritional and electrolyte issues, inhalation injuries and the amount of movement during procedures to wash patients, change drapes and access different anatomical sites. The appropriate execution of surgery is therefore of the utmost importance for both minor and major procedures.

Objective. To review the peri-operative management and standard of surgical care of burnt children.

Methods. This was a retrospective review and analysis of standard peri-operative care of burnt children at Red Cross War Memorial Children's Hospital, Cape Town, South Africa. A total of 558 children were operated on and supervised by the first author. Factors that could adversely affect surgical and anaesthetic outcomes were identified.

Results. There were 257 males and 301 females in this study, with an average age of 50.1 months and average weight of $19.5 \mathrm{~kg}$. The total body surface area involved was $1-80 \%$, with an average of $23.5 \%$. Inhalational injury was present in $11.3 \%$, pneumonia in $13.1 \%$, wound sepsis in $20.8 \%$, and septicaemia in $9.7 \%$, and organ dysfunction in more than one organ was seen in $6.1 \%$. The average theatre temperature during surgery was $30.0^{\circ} \mathrm{C}$. Core temperatures recorded at the start, halfway through and at completion of surgery were $36.9^{\circ} \mathrm{C}, 36.8^{\circ} \mathrm{C}$ and $36.5^{\circ} \mathrm{C}$, respectively. The average preoperative and postoperative haemoglobin levels were $11.28 \mathrm{~g} / \mathrm{dL}$ and $9.64 \mathrm{~g} / \mathrm{dL}$, respectively. Blood loss was reduced by the use of clysis from $1.5 \mathrm{~mL} / \mathrm{kg} / \%$ burn to $1.4 \mathrm{~mL} / \mathrm{kg} / \%$ burn. Adverse intraoperative events were seen in $17.6 \%$ of children. Conclusion. Burn surgery is a high-risk procedure and comorbidities are common. Anaesthesia and surgery must be well planned and executed with special reference to temperature control, rapid blood loss, preceding respiratory illnesses and measures to reduce blood loss.
\end{abstract}

S Afr Med J 2016;106(11):1114-1119. DOI:10.7196/SAMJ.2016.v106i11.10938

Surgery has become an integral component of total burn care. There are, however, a multitude of challenges facing a child in the peri-operative period, especially for burns $>30 \%$ of the total body surface area (TBSA). These challenges include patient factors, anaesthetic considerations, surgical aspects, theatre variables and availability of consumables. Anaesthetic considerations include airway management, vascular access, intensive monitoring, fluid and electrolyte imbalances, frequent intraoperative positional changes, altered temperature regulation, sepsis, cardiovascular instability, altered pharmacokinetics and increased requirements for analgesia and postoperative pain management. ${ }^{[1,2]}$

Thorough evaluation and stabilisation are prerequisites. There are no contraindications to surgery, apart from those that would disqualify the child from having general anaesthesia.

Surgical considerations include the removal of small to extensive eschars, haemorrhage control, donor skin procurement and resurfacing of the excised areas. Critical theatre variables include environmental temperature control, availability of consumables and staff experience. ${ }^{[3]}$

Although surgery for burns follows a standard procedure, it remains a high-risk procedure. This prospective study was designed to identify factors that could adversely affect surgical and anaesthetic outcomes.
Ethical permission was granted by the Human Research Ethics Committee, University of Cape Town (ref. no.: 765/2014).

\section{Methods}

To ensure a true reflection of the peri-operative process and standard of surgical care that children received, only those who had been operated on, or directly supervised by the senior investigator, were included in the study. The senior surgeon was assisted by a medical officer and one or two surgical trainees. Surgical procedures did not include rehabilitation. Information was routinely collected during all surgical procedures for the purpose of auditing. A standard document recorded the important and critical aspects of the preoperative, operative and immediate postoperative periods. These included the cause of the burn, depth of the burn, TBSA involved, the day after the burn, and presence of compromising factors, such as inhalational injury, wound infection, septicaemia, and organ failure at the time of surgery. Anaesthetic and intraoperative factors taken note of were premedication, anaesthetic agents used, wound preparation, various surgical procedures, blood transfusions, theatre time and adverse intraoperative events. The evaluation was continued until the child had been returned in a stable condition to the intensive care unit (ICU) or the burns unit. Patient selection included all children needing surgery, who were 
referred for specialised care from the Western Cape and further afield. Procedures included escharotomy, dressing changes, application of a biosynthetic skin substitute or allograft, skin grafting or wound preparation for subsequent grafting, anaesthetic services for placement of central lines, evaluation of inhalational injury, removal of surgical clips, and wound preparation of septic or neglected burns. These procedures took place during 2013 2016. In 2013, 1196 patients were admitted and 685 operated on, during 2014, 1102 were admitted and 592 operated on, while in 2015 , 1133 were admitted and 599 operated on. These operative numbers included all the subgroups of the surgical procedures. Many of these patients were referred to the unit late from beyond the catchment area for the management of complicated burns. The children were taken to theatre only when they were haemodynamically and biochemically stable. Paracetamol, clonidine and gabapentin were routinely administered to all children as ward medication. The dedicated burns theatre was preheated to $28.0-32.0^{\circ} \mathrm{C}$ to aid in maintaining normothermia. General anaesthesia was always administered, with an inhalational agent or ketamine infusion as maintenance. The airway was managed in one of the following three ways: nasal oxygen; laryngeal mask; or intubation. Only when the World Health Organization (WHO) surgical check list was completed, was the placement of monitors, induction of anaesthesia, securing of the airway, placement of lines and dressing removals performed.

The entire patient, including the donor and recipient areas, was washed with chlorhexidine soap $1 \%$, followed by the topical application of $0.006 \%$ sodium hypochlorite solution for 20 minutes. ${ }^{[4]}$

Standard surgical techniques were used for tangential or fascial excisions, escharotomy, wound debridement and applications of synthetic skin substitutes or allografts. ${ }^{[4-6]}$

The amount excised at each procedure depended on the stability of the patient, size of the burn, availability of auto- and allografts or skin substitutes, volume of blood loss incurred during the procedure, and critical care considerations. Various blood conservation techniques were used, including diathermy coagulation, suture ligation, calcium-enriched alginate dressings and topical application of swabs or bandages soaked in 1:30 000 adrenaline solutions. During the latter half of the audit, subeschar injections (clysis) of bupivacaine and adrenaline to the selected recipient and donor site/s were routinely given. ${ }^{[7]}$

\section{Clysis formulation}

- One ampule bupivacaine $(10 \mathrm{~mL}=50 \mathrm{mg})+$ 1 ampule adrenaline $(1 \mathrm{~mL}=1 \mathrm{mg})$ mixed together to total $11 \mathrm{~mL}$.

- An amount of $4.4 \mathrm{~mL}$ of this mixture should be added to $200 \mathrm{~mL}$ normal saline or Ringer's lactate.

- This constitutes a formulation of bupivacaine $0.01 \%$ and adrenaline 1:500 000 .

- Maximum dose of this solution: $20 \mathrm{~mL} / \mathrm{kg}$.

- It can then be administered into the subeschar and donor area before or immediately after procurement.

The need for blood transfusion was determined by haemoglobin concentration, cardiovascular stability, and likelihood of continued blood loss, as judged by the anaesthetist. Only packed red cells were used. Patients were transferred from the recovery room to the burns unit when they were alert, cardiovascular and respiratory functions had stabilised, pain control was good, and they were normothermic.

\section{Results}

A total of 558 consecutive children were operated on, all under the supervision of the main author; 257 were males and 301 females. Their average age was $50.1(1-154)$ months (Fig. 1) and average weight $19.5(4-60) \mathrm{kg}$. Their demographic profile is depicted in Table 1 . As expected, hot liquid and fire were the most common causes of burns, 206 child-

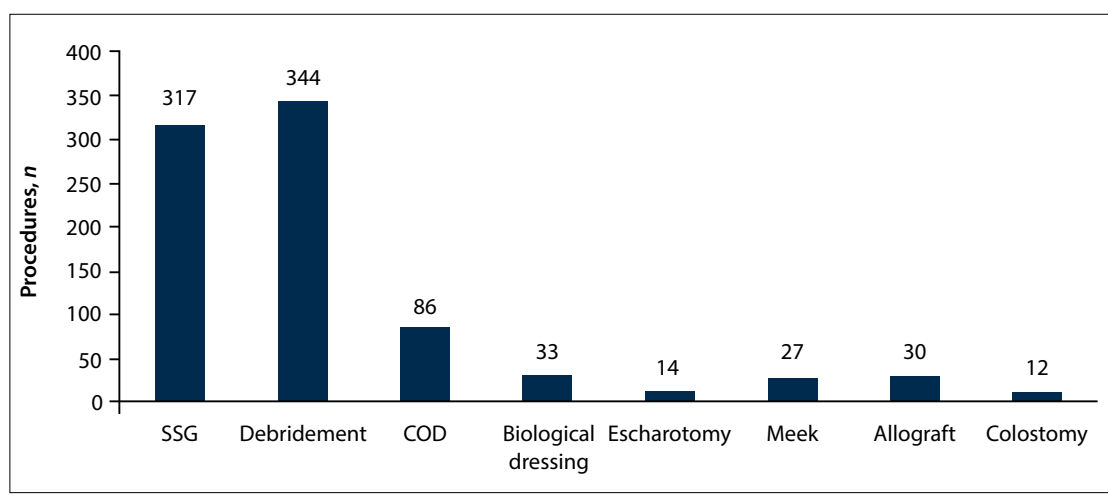

Fig. 1. Surgical procedures performed ( $S S G=$ split skin graft; $C O D=$ change of dressings).

ren had deep partial-thickness burns, and 277 had full-thickness burns. TBSA burnt ranged from $1 \%$ to $80 \%$, with an average of $23.5 \%$.

Children were significantly compromised at the time of surgery. Inhalational injury was present in $63(11.3 \%)$, pneumonia in 73 (13.1\%), wound sepsis in $116(20.8 \%)$, septicaemia in 54 (9.7\%), and 34 (6.1\%) had more than one organ dysfunction. Antibiotics were commenced prior to surgery in 162 children; an additional 40 were not administered antibiotics before the operation, but received an intraoperative dose. Antibiotics were continued postoperatively in 138 children.

Central lines were placed in 126 children. These were used in patients with large burns, or where peripheral access could not be attained in smaller burns. Ultrasound imaging was used as guidance for central line placement in all cases. Until the initiation of preoperative fasting, feeding was provided orally to 344 children and via nasogastric tube to 214. Oral premedication was given to 345 children. Midazolam was administered to the majority $(n=271)$, followed by clonidine

\begin{tabular}{|c|c|c|}
\hline Patients $(N=558)$ & $n$ & Range \\
\hline Age & & 1 - 154 mo. \\
\hline Neonate & 3 & \\
\hline 1 mo. - 2 yr & 199 & \\
\hline $3-4 \mathrm{yr}$ & 110 & \\
\hline $5-8 y r$ & 151 & \\
\hline $9-12 \mathrm{yr}$ & 72 & \\
\hline$>12 \mathrm{yr}$ & 15 & \\
\hline \multicolumn{3}{|l|}{ Gender } \\
\hline Female & 301 & \\
\hline Male & 257 & \\
\hline \multicolumn{3}{|l|}{ Causes } \\
\hline Hot water & 291 & \\
\hline Fire & 230 & \\
\hline Contact & 15 & \\
\hline Electrical & 4 & \\
\hline Other & 14 & \\
\hline TBSA (\%) & & $1-80$ \\
\hline$<10$ & 171 & \\
\hline $10-20$ & 123 & \\
\hline $21-30$ & 71 & \\
\hline$>30$ & 193 & \\
\hline Average & 25 & \\
\hline \multicolumn{3}{|l|}{ Depth } \\
\hline Full thickness & 277 & \\
\hline Partial thickness & 206 & \\
\hline Combination & 54 & \\
\hline
\end{tabular}


$(n=27)$, and a combination of trimeprazine and droperidol $(n=21)$. No premedication was given to children who were on sedation in ICU, those $<1$ year of age, $<10 \mathrm{~kg}$, or for emergency procedures.

The average theatre temperature was $30.0^{\circ} \mathrm{C}\left(21.7-36.2^{\circ} \mathrm{C}\right)$. The mean initial core temperature was measured as $36.9^{\circ} \mathrm{C}\left(34.0-40.0^{\circ} \mathrm{C}\right)$ at the beginning of the surgical procedure, as $36.8^{\circ} \mathrm{C},\left(29.8-40.0^{\circ} \mathrm{C}\right)$ halfway through the procedure, and as $36.5^{\circ} \mathrm{C}\left(33.0-40.0^{\circ} \mathrm{C}\right)$ at the conclusion of the procedure. The lowest postoperative temperature recorded was $33.0^{\circ} \mathrm{C}$ in a child with a $56 \% \mathrm{TBSA}$, in whom $25 \%$ was excised and grafted, with a theatre temperature of $32.0^{\circ} \mathrm{C}$. One child was hyperthermic at the conclusion of the procedure. His TBSA burnt was 53\%, he had pneumonia and organ failure, and wound debridement was performed.

A list of anaesthetic agents used in conjunction with each of the three methods of airway management is given in Table 2.

Induction of anaesthesia was either with sevoflurane or an intravenous agent (propofol or ketamine), depending on availability of intravenous access and patient preference (especially in older children). After induction of anaesthesia and establishment of intravenous access, sevoflurane would usually be discontinued to save costs, and replaced with isoflurane for maintenance or a total intravenous anaesthetic (TIVA) using ketamine. Where ketamine TIVA was used in children who were taken to theatre unintubated, spontaneous respiration could be maintained with the addition of nasal oxygen and measurement of capnography via nasal cannula. Some children had increased ketamine requirements owing to tolerance or pharmacokinetic changes, which required the addition of low concentrations of an inhalational agent via nasal cannula. In some patients propofol was added to ketamine TIVA to ensure adequate depth of anaesthesia.

Ketamine was not only used for TIVA, but was also added to isofluranebased techniques in analgesic doses. Morphine, ketamine and intravenous paracetamol formed the basis of most analgesic combinations. As most ward patients received regular paracetamol, dosing in theatre had to be timed to match the ward prescription, or had to be omitted to prevent overdosing. In a few patients in whom pain control was particularly challenging, clonidine was administered intravenously. Clonidine also decreases requirements for anaesthetic agents and opposes the sympathomimetic effects of ketamine; therefore, additional postoperative sedation may be beneficial in some patients. Fentanyl was of particular use during procedures with short-lived stimulation and/or with little postoperative pain. When combined with longer-acting agents, such as morphine, this allowed for a higher turnover of patient numbers.

Table 3 displays the total anaesthetic and surgical times and, in addition, anaesthetic and surgical times in relation to the time per percentage burn. The administration of safe anaesthesia in small compromised children was done taking all precautions into account.

The various surgical procedures performed are depicted in Fig. 1, and consisted of wound debridement and preparation, tangential and full excisions, placement of biological dressing, removal of clips, Meek micrografting and the application of allografts. The time interval from sustaining the burn to the various surgical procedures is depicted in Fig. 2.

The average preoperative haemoglobin was $11.3(6.5-17.2) \mathrm{g} / \mathrm{dL}$ and the average postoperative haemoglobin at the conclusion of the operation was $9.6(5.4-15.1) \mathrm{g} / \mathrm{dL}$.

A total of 143 children required blood transfusion for split skin grafts, as the only procedure with a mean TBSA of 7 (1 - 45)\%. These children received on average $254 \mathrm{~mL}$ of packed red blood cells $(50-1000 \mathrm{~mL})$. Of these, 114 received clysis, with an average TBSA of $10(1-28) \%$. The blood volume transfused was 233 (60$720) \mathrm{mL}$, equating to a $1.36 \mathrm{~mL} / \mathrm{kg} / \%$ burn. Clysis has now become the standard of care and should not be omitted.
Table 2. Airway management and agents used in patients $(n)$

\begin{tabular}{lllll}
\hline Agent & Intubated & Laryngeal mask & Nasal oxygen & Total \\
\hline Sevoflurane & 125 & 113 & 33 & 271 \\
Isoflurane & 158 & 142 & 11 & 311 \\
Ketamine & 146 & 90 & 126 & 362 \\
Morphine & 161 & 141 & 90 & 392 \\
Intravenous & 126 & 135 & 63 & 324 \\
paracetamol & & & & \\
Propofol & 63 & 62 & 14 & 139 \\
Fentanyl & 123 & 118 & 43 & 284 \\
Clonidine & 13 & 12 & 7 & 32 \\
Other & 29 & 19 & 12 & 60
\end{tabular}

Table 3. Average theatre time per percentage burn

\begin{tabular}{lll}
\hline Burn & Hot water & Fire \\
\hline $\begin{array}{l}\text { Average TBSA (\%) } \\
\text { Average total time (min) }\end{array}$ & $37.8(1-50)$ & $12.1(1-60)$ \\
$\quad \begin{array}{l}\text { Anaesthetic } \\
\quad \text { Operative }\end{array}$ & $36.0(15-150)$ & $84.8(15-270)$ \\
$\begin{array}{l}\text { Average time/TBSA (min/\%) } \\
\quad \text { Anaesthetic }\end{array}$ & 1.5 & $64.4(6-250)$ \\
$\quad$ Operative & 1.0 & 7.0 \\
\end{tabular}

Adverse intraoperative events were seen in 98 (17.6\%) children. Hypothermia $\left(<35^{\circ} \mathrm{C}\right)$ was present in 15 , equipment failure occurred in 14 , and airway problems in 29 . The last included intraoperative extubation $(n=3)$, bronchospasm $(n=4)$, postintubation stridor $(n=14)$ and respiratory arrest $(n=1)$. Of the children who suffered stridor, it was noted that 5 had upper-respiratory tract infections and 9 the laryngeal mask airway (LMA) for airway maintenance. Upper-respiratory tract infections occurred in 4 children with bronchospasm. Airway patency was secured with endotracheal tubes in 3 children and with LMA in 1 child. In the child with respiratory arrest circumferential thoracic bandaging was too tight; it had to be released to restore spontaneous respiration. One child woke up during surgery (ketamine tachyphylaxis) and 6 children had delayed anaesthetic reversal. Five children were hypotensive at the end of the surgical procedure following large excisions and slow replacement of blood loss. Excessive bleeding was encountered in 35 children.

Furthermore, we commonly use two concentrations containing adrenaline - one for topical use only at 1:30 000 IU and the other at 1:500 $000 \mathrm{IU}$ for subcuticular clysis in the management of intraoperative haemostasis. After the review was completed, these two solutions were exchanged in error, resulting in the higher concentration of adrenaline being injected subcutaneously for haemostatic purposes. Consequently, there were a few hours of extreme elevation in systolic blood pressure of $220 \mathrm{mmHg}$. Fortunately, the pharmacological effect resolved rapidly, with no adverse consequences. Since then, two drops of methylene blue have been added to the topical adrenaline routinely to avoid future complications.

\section{Discussion}

Burn care in South Africa (SA) is predominantly emergency driven, where a large number of burnt children are often being operated on 


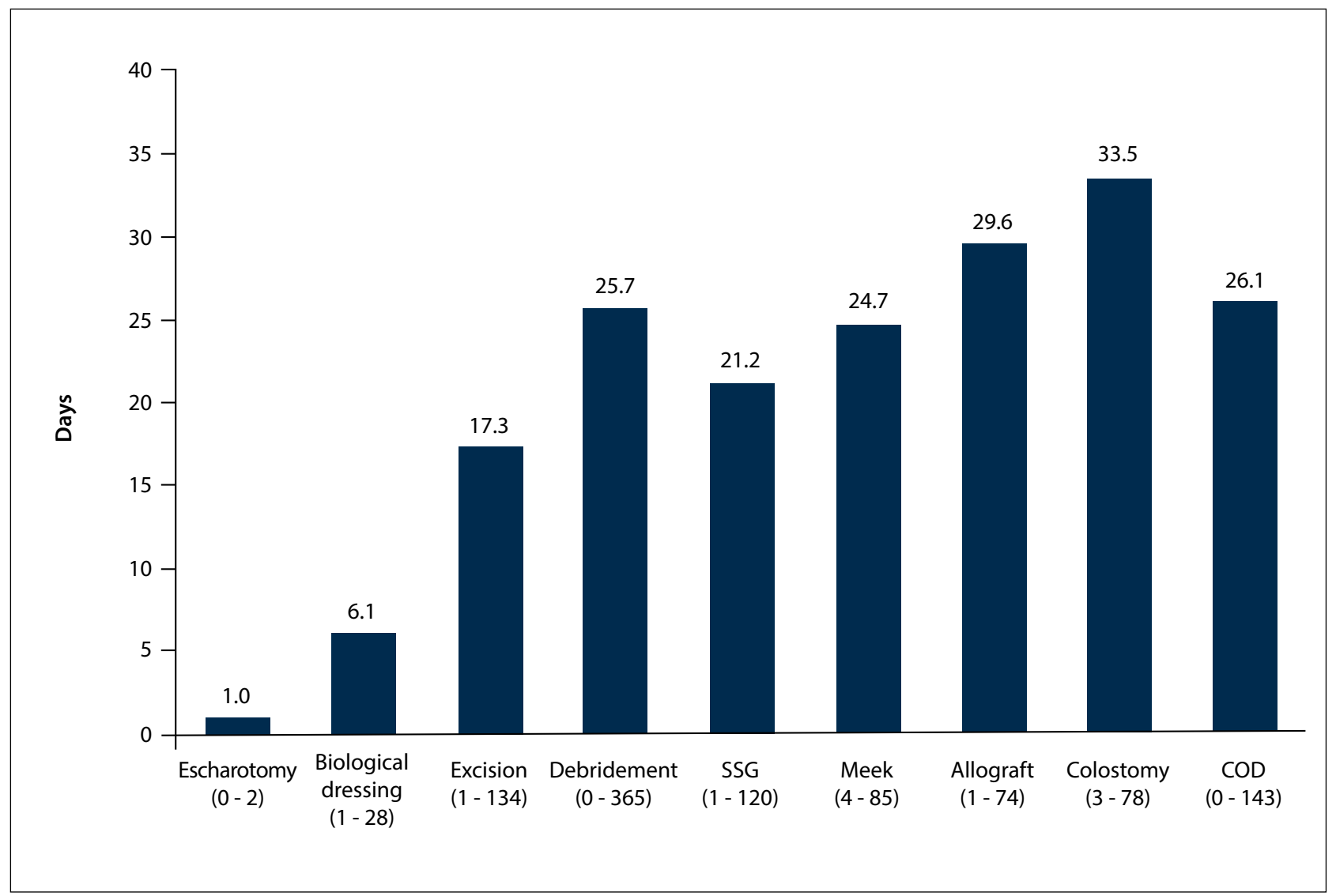

Fig. 2. Average days to the surgical procedure (range given in brackets).

by surgeons who lack the tools or training in centres that are not dedicated burn units. ${ }^{[8]}$

This audit of surgical practice, in an established paediatric burn centre, is the first of its kind in SA. It could therefore serve as a reference point for the basic requirements needed to achieve reasonable outcomes in an environment of severe fiscal restraints, inadequate facilities and inexperienced personnel. As the unit also serves as a referral centre, many neglected, septic, failed surgical procedures or compromised patients were referred for rescue or further surgical procedures. Many of these patients came from very poor socioeconomic environments, with less than ideal hygienic standards, and with nutritional deficiencies and concurrent infections. They often required a period of preparation outside of the unit's procedural standards before surgical procedures could be performed.

Transport to theatre and transfer of the patient from the bed onto the operating table must be safe and comfortable for the child, with one of the parents in attendance..$^{[1,2,9]}$

We are fortunate to have a dedicated burns theatre with the required facilities for heating, correct anaesthetic equipment, specially designed operating table and appropirate consumables (Fig. 3).

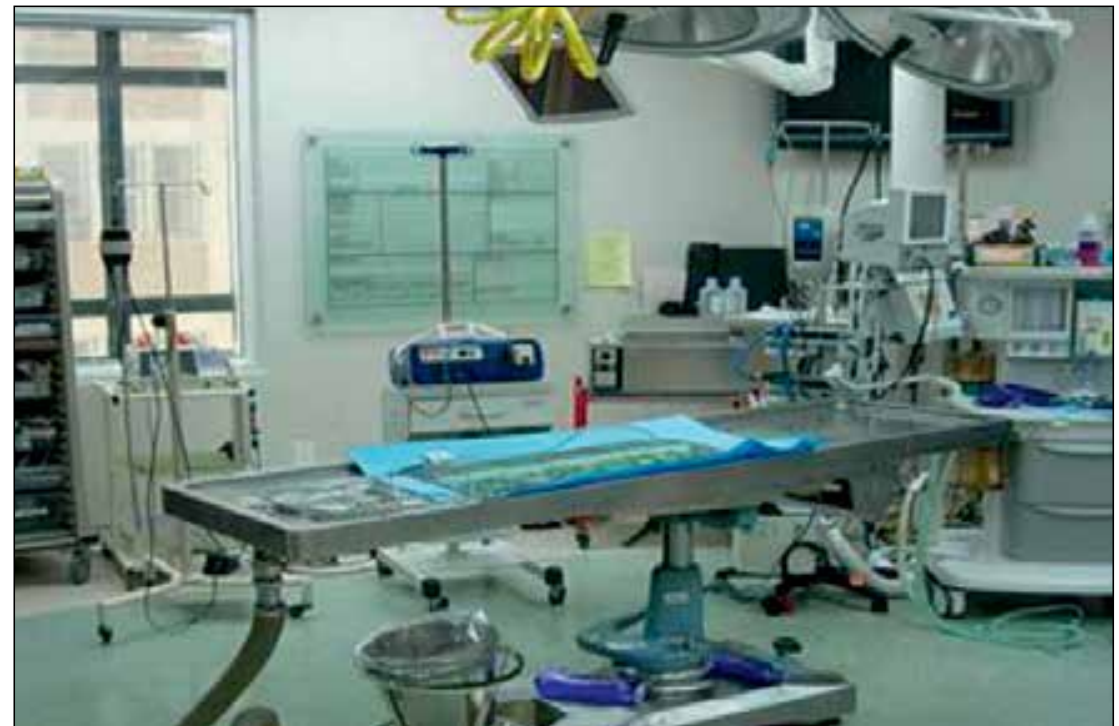

Fig. 3. A modern and well-equipped theatre. Note the specialised operating table and the electrocautery mattress.

Every effort was made to premedicate the children with sedatives and anxiolytic agents to alleviate fear and pain, and to reduce adverse physiological and long-term psychological effects. Premedication was withheld from infants, those on intravenous morphine or sedation in the ICU, and emergency cases.
Preoperative fasting was scheduled not to exceed 6 hours, but in cases of large burns, with frequent visits to theatre, nasojejunal tube feeds were administered up to 2 hours before the scheduled procedure. The standard practice in this unit is not to give continuous nasojejunal feeding intraoperatively, although there is evidence to 
Table 4. Ketamine TIVA v. ETT with inhalational agent

\begin{tabular}{|c|c|c|c|}
\hline \multicolumn{2}{|c|}{ Ketamine TIVA } & \multicolumn{2}{|c|}{ ETT with inhalational agent } \\
\hline Benefits & Drawbacks & Benefits & Drawbacks \\
\hline $\begin{array}{l}\text { Haemodynamic stability in the } \\
\text { face of blood loss }\end{array}$ & $\begin{array}{l}\text { Increased heart rate and blood } \\
\text { pressure confound assessment of } \\
\text { volume status }\end{array}$ & $\begin{array}{l}\text { Less exaggerated effect on blood } \\
\text { pressure and heart rate; easier to } \\
\text { gauge volume status }\end{array}$ & $\begin{array}{l}\text { More likely to decompensate with } \\
\text { major blood loss }\end{array}$ \\
\hline $\begin{array}{l}\text { No instrumentation of the airway } \\
\text { - will not contribute to stridor }\end{array}$ & $\begin{array}{l}\text { Airway not protected against } \\
\text { aspiration. No protection against } \\
\text { laryngospasm }\end{array}$ & $\begin{array}{l}\text { Can protect against aspiration and } \\
\text { laryngospasm during anaesthesia }\end{array}$ & $\begin{array}{l}\text { Airway instrumentation may } \\
\text { contribute to stridor }\end{array}$ \\
\hline $\begin{array}{l}\text { Maintains functional residual } \\
\text { capacity }\end{array}$ & $\begin{array}{l}\text { May cause secretions. No access } \\
\text { to suction secretions or recruit } \\
\text { collapsed alveoli }\end{array}$ & $\begin{array}{l}\text { Can use ETT to suction lungs and } \\
\text { recruit alveoli }\end{array}$ & $\begin{array}{l}\text { Loss of functional residual capacity } \\
\text { associated with inhalational agents, } \\
\text { muscle relaxants and intubation }\end{array}$ \\
\hline $\begin{array}{l}\text { Easy to change patient position } \\
\text { without dislodging ETT }\end{array}$ & $\begin{array}{l}\text { Changes in patient position may } \\
\text { obstruct the airway }\end{array}$ & $\begin{array}{l}\text { Protects the patient's airway in all } \\
\text { positions }\end{array}$ & $\begin{array}{l}\text { ETT may dislodge easily and may } \\
\text { be difficult to secure }\end{array}$ \\
\hline $\begin{array}{l}\text { Provides good access to the face } \\
\text { for surgery }\end{array}$ & $\begin{array}{l}\text { Cleaning fluid and blood may be } \\
\text { aspirated into the lungs } \\
\text { Needs good intravenous access, } \\
\text { and may require separate lines for } \\
\text { TIVA and volume replacement }\end{array}$ & $\begin{array}{l}\text { Protects the airway against } \\
\text { external fluids } \\
\text { Administration of gas not } \\
\text { dependant on intravenous access }\end{array}$ & $\begin{array}{l}\text { ETT and methods used to secure } \\
\text { ETT may hinder surgery }\end{array}$ \\
\hline Provides additional analgesia & Tolerance may develop & No tolerance & No analgesic effect \\
\hline Patient not paralysed & $\begin{array}{l}\text { Involuntary movements may } \\
\text { interfere with surgery }\end{array}$ & Patient immobile & $\begin{array}{l}\text { Paralysed patients are at particular } \\
\text { risk of awareness }\end{array}$ \\
\hline
\end{tabular}

suggest that doing so does not increase the risk of aspiration. ${ }^{[10]}$

Vascular access, especially in small infants, was trying. At times it was necessary to place catheters through burnt tissue and to use ultrasonographic guidance to check patency and locate vessels. The preferred route in small surface area burns was peripheral, and in larger burns, either the internal jugular, subclavian or femoral routes were used. Routine anaesthetic monitoring was used in most cases, reserving invasive monitoring for cases where massive blood loss was anticipated. It often required creative nonstandard thinking and moving monitors during surgery, as different areas were operated on in turn. Securing the airway may be challenging. The Gray-Rode technique of securing a naso- or orotracheal tube has proved an indispensable method for patients requiring frequent positional changes and when surgery to the face and head was required. ${ }^{[11]}$

The anaesthetic method was dictated by patient needs, the anticipated procedure, individual choice of anaesthetist, and if the trachea had been damaged by an inhalation injury or previous intubation. ${ }^{[2]}$

In general, three techniques were used for airway management, i.e. tracheal intubation, supraglottic airway (LMA), or spontaneous ventilation with supplemental oxygen via nasal cannula as part of a ketamine TIVA. Maintenance of anaesthesia was either with isoflurane or ketamine TIVA. A supraglottic airway has the advantage of being noninvasive, but is often inappropriate in patients with facial burns, or where changes in patient positioning are planned. In the latter, the choice lies between endotracheal tube (ETT) intubation or ketamine TIVA without manipulation of the airway. Table 4 lists some benefits and drawbacks of each of these techniques. The series by McCall et al. ${ }^{[12]}$ with burnt children demonstrated that the use of LMAs was a safe and efficacious method to maintain an open airway.

Adverse respiratory events directly related to the method of anaesthesia were seen in $3 \%$ of the children, which represents the highest incidence among all surgical theatres in our theatre complex. Factors contributing to this included preceding upper-respiratory tract infections (50\%), inhalational injuries, use of the LMA system (55\%) and ETT intubation in children with upper-respiratory tract infections.

Fibreoptic intubation was very rarely needed, even with compromised upper-airway burns. We have found video laryngoscopy to be very useful in some situations. No tracheostomies were performed.

Hypothermia was a significant problem. Utmost care was taken to maintain core body temperature during the intraoperative period, but despite this the lowest core temperature recorded was $33.0^{\circ} \mathrm{C}$. Preventable measures included a very uncomfortable ambient theatre temperature of $28.0-32.0^{\circ} \mathrm{C}$ and warmed intravenous fluids. On average, there was only a $1.0^{\circ} \mathrm{C}$ decrease in core temperature.

Since the introduction of routine preoperative washing with warm chlorhexidine soap $1 \%$ followed by the topical application of sodium hypochlorite $0.006 \%$ as standard of care of our practice, donor site Pseudomonas infections are not as common as previously seen. ${ }^{[4]}$

Burn surgery comprises $11 \%$ of all surgical procedures performed annually in the operation suite and the unit's philosophy follows a standard surgical approach to burn care. $^{[13]}$

Partial thickness wounds were treated with short- and long-acting topical antiseptic agents, while burns of an indeterminate depth (especially hot water burns) were observed and dressed for 10 - 14 days before the final decision whether to operate was made. Deep burns were excised and grafted as soon as the patient was stable. The amount excised at each procedure depended on the stability of the patient, burn size, availability of auto- and allografts or skin substitutes, volume of blood loss incurred during the procedure, and critical care considerations. Colostomies were performed only for major gluteal, perineal and upperthigh burns.

Unfortunately, many of the procedures were delayed or done outside the ideal 
period, necessitating a different approach. These included wound preparation of chronic infected wounds, wounds that were inadequately excised, removal of septic granulation tissue, and waiting for suitable allografts.

Blood loss during surgery may be substantial from the excised and donor sites. ${ }^{[7,14]}$ Blood loss was not measured calorimetrically, the transfusion volume was based on the presurgical haemoglobin level, and the volume transfused was decided clinically by the attending anaesthetist. Fresh-frozen plasma was not used. There are many techniques to reduce blood loss. Pre-excisional clysis of the recipient area and post-procurement clysis of the donor site/s have become standard practice to reduce bleeding from the donor and recipient areas. ${ }^{[7]}$ We have not observed any cardiac arrhythmias following clysis, but would caution about its routine use with pre-existing cardiac abnormalities, especially in conjunction with inhalation anaesthesia. This technique does not compromise burndepth assessments or impair graft survival.

Adverse intraoperative events are to be anticipated in a setting of often critically ill children. Factors such as haemodynamic and respiratory compromise, altered pharmacodynamics, frequent positional changes, large excisions, rapid blood loss and a high risk of hypothermia all need consideration. Despite measures to prevent or minimise adverse events, 95 children were compromised, often with life-threatening complications, including hypothermia or adverse airway problems (including respiratory arrest, waking up during surgery, delayed recovery from anaesthesia and hypotension). Of note, most of the anaesthetic and hypothermic complications occurred in infants.

As this was a retrospective analysis, a limitation identified was missing information. It was calculated to be approximately $2 \%$ of our captured data.

Burnt patients, depending on the stage of their burn, can have significantly altered inter- and intra-individual variations in drug pharmacokinetics and pharmacodynamics. Such studies fell outside the scope of the current article.

\section{Conclusion}

The burnt child faces significant challenges peri-operatively. This review of our operative practice provided insight into existing therapeutic approaches, with the following conclusions: the environmental temperature must be adequate to ensure normothermia; cognizance must be taken of the potential for rapid blood loss; and preceding upper-respiratory tract infections often lead to laryngobronchospasm. However, the need for surgery cannot be indefinitely postponed, and therefore will always put the respiratory system at risk. This may require hypervigilance on the part of the anaesthetist. Owing to the potential adverse effects of blood transfusions, blood loss must be minimised by the use of clysis.

\footnotetext{
1. Fuzaylov G, Fidkowski CW. Anaeshetic considerations for major burn injury in paediatric patients. Pediat Anaesth 2009;19(3):202-211. DOI:10.111/j1460-9592.2009.02924.x

2. Bittner EA, Shank E, Woodson L, Martyn JAJ. Acute and perioperative care of the burn-injured patient. Anesthesiology 2015;122(2):448-464. DOI:10.1097/ALN.0000000000000559

3. Sheridan RL, Schnitzer JJ. Management of the high-risk pediatric burn patient. J Pediatr Surg 3. Sheridan RL, Schnitzer JJ. Management of the high
2001;36(1):1308-1312. DOI:10.1053/jpsu.2001.25805

4. Coetzee E, Whitelaw A, Kahn D, Rode H. The use of topical, unbuffered $0.006 \%$ sodium hypochlorite in the management of burn wound infection. Burns 2012;38(4):529-533. DOI:10.1016/j. burns.2011.10.008 5. Besner GE, Grewal H. Surgical treatment of burns. 2012. http://emedicine.medscape.com/ article/934173-overview (accessed 26 September 2016).

6. Rode H, Heimbach D. Thermal injury. In: Spitz L, Coran AG, eds. Operative Pediatric Surgery. Ch. 101. 7th ed. London: CRC Press, 2013.

7. Sheridan RL, Szyfelbein SK. Staged high-dose epinephrine clysis is safe and effective in extensive tangential burn excisions in children. Burns 1990;25(8):745-748. DOI:10.1016/S0305-4179(99)00088/1 . Allorto NL, Zoepke S, Clarke DL, Rode H. Burn surgeons in South Africa - a rare species. S Afr Med J 2016;106(2):186-188. DOI:10.7196/SAMJ.2016v106i9.10852

9. Beushausen T, Mucke K. Anesthesia and pain management in pediatric burn patients. Pediatr Surg Int 1997;12(5):327-333. DOI:10.1007/BF01076931

10. Jenkins ME, Gottschlisch MM, Warden GD. Enteral feeding during operative procedures in thermal injuries. J Burn Care Rehabil 1994;15(2):199-205. DOI:10.1097/00004630-199403000-00019

injuries. J Burn Care Rehabil 1994;15(2):199-205. DOI:10.1097/00004630-199403000-00019
11. Gray R, Rode H. Intra-operative endotracheal tube stabilization for facial burns. Burns 2010;36(4):572-575. DOI:10.1016/.j.burns.2009.11.004

12. McCall JE, Fischer CG, Schomaker E, Young JM. Laryngeal mask airway use in children with acute burns: Intraoperative airway management. Paediatr Anaesth 1999;9(6):515-520. DOI:10.1046/j.1460-9592.1999.00407.x 13. Ong YS, Samuel M, Song C. Meta-analysis of early excision of burns. Burns 2006;32(2):145-150. DOI:10.1016/j.burns.2005.09.005

14. Desai MH, Herndon DN, Broemeling L, et al. Early burn wound excision significantly reduces blood loss. Ann Surg 1990;211(6):753-759. DOI:10.1097/00000658-199006000-00015
}

Accepted 13 May 2016. 